Article

\title{
A General Micro-Level Modeling Approach to Analyzing Interconnected SDGs: Achieving SDG 6 and More through Multiple-Use Water Services (MUS)
}

\author{
Ralph P. Hall ${ }^{1, *}$, Shyam Ranganathan ${ }^{2}$ and Raj Kumar G. C. ${ }^{1}$ \\ 1 School of Public and International Affairs, Virginia Tech, Blacksburg, VA 24061, USA; rajgc@vt.edu \\ 2 Department of Statistics, Virginia Tech, Blacksburg, VA 24061, USA; shyam81@vt.edu \\ * Correspondence: rphall@vt.edu; Tel.: +1-540-231-7332 \\ Academic Editor: Christian Zurbrügg \\ Received: 12 December 2016; Accepted: 14 February 2017; Published: 21 February 2017
}

\begin{abstract}
The 2030 agenda presents an integrated set of Sustainable Development Goals (SDGs) and targets that will shape development activities for the coming decade. The challenge now facing development organizations and governments is how to operationalize this interconnected set of goals and targets through effective projects and programs. This paper presents a micro-level modeling approach that can quantitatively assess the impacts associated with rural water interventions that are tailored to specific communities. The analysis focuses on how a multiple-use water services (MUS) approach to SDG 6 could reinforce a wide range of other SDGs and targets. The multilevel modeling framework provides a generalizable template that can be used in multiple sectors. In this paper, we apply the methodology to a dataset on rural water services from Mozambique to show that community-specific equivalents of macro-level variables used in the literature such as Cost of Illness (COI) avoided can provide a better indication of the impacts of a specific intervention. The proposed modeling framework presents a new frontier for designing projects in any sector that address the specific needs of communities, while also leveraging the knowledge gained from previous projects in any country. The approach also presents a way for agencies and organizations to design projects or programs that bridge sectors/disciplines (water, irrigation, health, energy, economic development, etc.) to advance an interconnected set of SDGs and targets.
\end{abstract}

Keywords: sustainable development goals; water; multiple-use water services; rural; peri-urban; cost-benefit analysis; multilevel modeling framework

\section{Introduction}

In 2015, the United Nations (UN) General Assembly adopted the 2030 agenda that established 17 Sustainable Development Goals (SDGs) and 169 targets to guide the next 15 years of development [1]. The creation of the 2030 agenda emerged from an unprecedented global dialogue that included thematic discussions, national consultations in over 80 countries, and the development of numerous reports. This process created a set of goals and targets described as "integrated and indivisible, global in nature and universally applicable" [1] (p. 13). The challenge now facing countries and development organizations is how to operationalize an interconnected set of goals and targets, especially given the inherent contradictions between some of these goals such as economic development and environmental protection as evidenced by existing trajectories of development [2]. To this end, work has begun on how to conceptually map the influence of one SDG or target on another [2,3] and how advancing the SDGs as a whole might impact specific objectives such as improving health [4]. 
In this paper, we consider SDG 6-to "ensure availability and sustainable management of water and sanitation for all" [1] (p. 18) —and focus specifically on the interconnected impacts of realizing this goal in the context of rural water supply. The question of how water and sanitation services are interconnected with other critical development goals has been the subject of much debate in the human rights arena [5-10]. Since water is vital to livelihoods and has direct gender-related impacts [11-13], its role in realizing a broad range of socio-economic human rights has been well documented [7]. The interconnections that exist between the recently established human right to water and sanitation [14] and human rights related to living a healthy and productive life, also exist between SDG 6 and the other SDGs and targets.

Over the past decade, increasing attention has been given to how rural and peri-urban households use water $[15,16]$. Whereas water services provision has traditionally focused on providing water for a single use-i.e., for domestic needs (such as drinking, cooking, washing, or bathing) or for irrigation purposes [17] - there is growing evidence of the need to provide water for productive uses (such as raising livestock, growing crops/kitchen gardens, making bricks, etc.) around the homestead [18,19]. Research conducted in 147 rural communities in Colombia, Senegal, and Kenya with small-scale reticulated systems, found that three quarters of households were using their water to support productive activities, irrespective of whether this type of water use was permitted $[7,20]$. The productive activities in these communities predominantly focused on raising livestock and small-scale agriculture or gardening around the homestead, followed by water-based commercial or service activities. Around one half of households surveyed in all three countries earned an income from their water-related productive activities and this income represented around one half of a household's total income [7]. In Senegal, the engagement of rural households in the productive use of water was also found to be associated with better technical performance of water supply systems [20] and provided women with opportunities to engage in livelihood diversification strategies [21].

When compared against the single-use approach to rural water supply, multiple-use water services (MUS) holds the potential to realize a more comprehensive and interconnected set of water-related outcomes [7]. This potential-to alleviate poverty, enhance land and water productivity, improve rural livelihoods, promote gender equity, etc.-meant it aligned well with several of the original set of eight millennium development goals (MDGs) [22]. Given the critical role of water in achieving the SDGs [23], this paper revisits MUS as providing a comprehensive and potentially efficient way to advance significant components of the 2030 agenda, especially in low income settings.

Section 2 defines MUS and summarizes the reinforcing connections that exist between an MUS approach and the SDGs; describes an approach to measuring the costs and benefits of MUS; and argues that a micro-modeling approach is needed to better estimate the impacts of MUS. Section 3 outlines the modeling framework and describes the data used to demonstrate the general modeling approach. Section 4 presents the modeling results that are then discussed in Section 5. Section 6 concludes the paper.

\section{Theoretical Development and Background}

\subsection{MUS and the SDGs}

MUS is described as "a public services approach that takes poor people's multiple water needs as the starting point for planning and providing water services" [24] (p. ix). It is a participatory and gender inclusive whole-water approach, focused on aligning domestic and productive water needs with available water sources, within the context of sustainable water resources management $[25,26]$. The MUS approach attempts to tailor the water services provided to the needs of each community, using a range of water supply technologies (e.g., rope pumps, handpumps, solar/wind pumps, rainwater systems, small-scale reticulated systems with household connections, public taps, cattle troughs, and/or water for small agricultural plots). This tailoring means that the components of an MUS project will vary by location and in response to community needs. 
In general, the MUS approach can be described as focusing on three interrelated objectives-i.e., increasing a community's access to water (for all uses), improving health, and enhancing livelihoods [25-27]. Thus, MUS interventions typically target these objectives within the context of improving the sustainability of the water services provided. It should be noted, however, that in practice the ability for an MUS program to address all three objectives depends on how funding can be used-i.e., to target improving access to water or a more comprehensive approach that also includes improving health and livelihoods as program outcomes. In this paper, an 'ideal' MUS approach is considered that advances all three of objectives in an integrated way, as described by $[24,26]$.

The scope of the MUS approach means that it holds the potential to specifically address SDG 6 and influence a wide range of other SDGs and targets.

Nilsson et al. [3] offer a conceptual framework to consider the relationships that may exist between the 17 SDGs and 169 targets. The framework provides seven types of interactions-i.e., +3 Indivisible, +2 Reinforcing, +1 Enabling, 0 Consistent, -1 Constraining, -2 Counteracting, and -3 Canceling [3]. While labelling an interaction between two goals or targets is somewhat subjective, the framework can help distinguish between interactions that are direct versus indirect, in both a positive and negative sense.

Using Nilsson et al.'s framework as a guide, we considered how an ideal MUS approach designed to ensure the "availability and sustainable management of water" (SDG 6) in a rural context might influence other SDGs and targets (see Table A1 in Appendix A). For example, improving access to water services can have a direct impact on income if the water is used to support income-generating productive activities around the homestead, and an indirect impact on educational attainment if any reduction in the time spent collecting water enables children to attend school. In the former example, productive activities depend on the water supplied, whereas in the latter example, water enables another activity to occur, but this activity could occur independent of the water supply service. In the context of Nilsson et al.'s [3] framework, direct interactions can be considered as either +3 Indivisible, +2 Reinforcing, -2 Counteracting, or -3 Canceling and indirect interactions as +1 Enabling or -1 Constraining.

Table 1 provides a summary of the six SDGs and related targets considered to be 'reinforced' by MUS. (The complete analysis of how an ideal MUS approach $[24,26]$ might influence the SDGs and targets is provided in Table A1 in Appendix A. The overall scope of the approach can be understood by reviewing the 'Relationship' column in Table A1.) Table 1 shows that an MUS approach could reinforce the SDGs focused on poverty (SDG 1), hunger (SDG 2), health (SDG 3), gender equality (SDG 5), inclusive growth (SDG 8), and income inequality (SDG 10). The MUS approach was also considered to have an indirect 'enabling' influence on the seven SDGs focused on education (SDG 4), energy (SDG 7), resilient infrastructure (SDG 9), resilience (SDG 11), sustainable consumption and production (SDG 12), climate change (SDG 13), and the sustainable use of ecosystems (SDG 15) (see Table A1 in Appendix A). The MUS approach was considered to have 'indivisible,' 'reinforcing,' and 'enabling' influences on the SDG 6 targets (Table A1).

While the MUS approach holds the potential to impact the SDGs, the provision of sustainable rural water services has proven to be challenging. Rural access to improved water services (primarily for domestic use) increased from $63 \%$ in 1990 to $84 \%$ in 2015 [12], yet it is common to find that around one-third of installed water points have failed within five years of installation [28]. In general, rural water services tend to be considered sustainable if they continue to function over their intended design life [29-33]. The sustainability of a service has been linked to factors such as designing a service in response to community demand, ensuring local financing and cost recovery, and promoting dynamic system operation and maintenance [30]. Harvey and Reed provide a useful definition of a sustainable water supply that extends this view to consider the ecological sustainability of the service: "A water service is sustainable if the water sources are not over-exploited but naturally replenished, facilities are maintained in a condition which ensures a reliable and adequate water supply, the benefits of the supply continue to be realized by all users indefinitely, and the service 
delivery process demonstrates a cost-effective use of resources that can be replicated" [31] (p. 7). The concept of MUS is consistent with these perspectives and pays specific attention to the 'benefits' of water services related to improving health and livelihoods. It is also argued that the income-related benefits of MUS may improve the financial health and technical sustainability of services, since users have increased income from water-related productive activities and, therefore, a willingness and ability to pay for these services $[18,19,24,34]$. This potential for MUS to enhance the sustainability of rural water supply services is the primary reason the approach was selected for this paper. Tables 1 and A1 (in Appendix A) provide additional insight into how an ideal MUS approach might also impact sustainable development as defined by the SDGs and targets.

Table 1. 'Reinforcing' relationships between the provision of rural water supply services (via MUS) and SDG targets.

\begin{tabular}{|c|c|c|}
\hline SDG Goal & SDG Target & Relationship \\
\hline $\begin{array}{l}\text { Goal 1: End poverty in all } \\
\text { its forms everywhere }\end{array}$ & 1.1 and 1.2 & $\begin{array}{l}\text { The provision of water for productive activities (e.g., } \\
\text { raising livestock, small-scale agriculture) can reduce } \\
\text { poverty via direct income or avoided expenditures }\end{array}$ \\
\hline $\begin{array}{l}\text { Goal 2: End hunger, achieve food } \\
\text { security and improved nutrition, and } \\
\text { promote sustainable agriculture }\end{array}$ & 2.1 and 2.2 & $\begin{array}{l}\text { The provision of water for productive activities can } \\
\text { directly reduce hunger via the consumption of crops } \\
\text { and livestock-related food products }\end{array}$ \\
\hline $\begin{array}{l}\text { Goal 3: Ensure healthy lives and } \\
\text { promote well-being for all at all ages }\end{array}$ & $3.1,3.2$, and 3.3 & $\begin{array}{l}\text { The provision of clean water for domestic uses (e.g., } \\
\text { drinking, cooking, washing, and bathing) is critical to } \\
\text { reducing mortality and water-borne diseases } \\
\text { The appropriate design of water services can reduce } \\
\text { water-related vectors/diseases such as malaria }\end{array}$ \\
\hline $\begin{array}{l}\text { Goal 5: Achieve gender equality and } \\
\text { empower all women and girls }\end{array}$ & $5.1,5.5,5.4$, and $5.5 a$ & $\begin{array}{l}\text { As the primary water collectors, improving access to } \\
\text { water, and including women in the management of } \\
\text { water services, will enable women to have more } \\
\text { control over their domestic, reproductive, and } \\
\text { productive activities, and improve women's } \\
\text { participation in leadership and decision-making roles }\end{array}$ \\
\hline $\begin{array}{l}\text { Goal 8: Promote sustained, inclusive, } \\
\text { and sustainable economic growth, full } \\
\text { and productive employment, and } \\
\text { decent work for all }\end{array}$ & $8.1,8.2$, and 8.3 & $\begin{array}{l}\text { Improving access to water and financial services will } \\
\text { reduce the time spent collecting water and enable } \\
\text { individuals, especially women, to engage in income } \\
\text { generating activities }\end{array}$ \\
\hline $\begin{array}{l}\text { Goal 10: Reduce inequality within and } \\
\text { among countries }\end{array}$ & 10.1 & $\begin{array}{l}\text { The provision of water for productive } \\
\text { activities can promote income growth, } \\
\text { especially for the poorest } 40 \text { percent of } \\
\text { the population who tend to live in rural areas }\end{array}$ \\
\hline
\end{tabular}

Realizing the SDG 6 target to achieve by 2030 "universal and equitable access to safe and affordable drinking water for all" [1] (p. 18), will require the careful analysis of the costs and benefits of different levels of access to rural water services. Such an analysis is needed to identify the service delivery approaches that demonstrate "a cost-effective use of resources" [31] (p. 7). By connecting an ideal MUS approach to the realization of SDG 6 (in a rural setting), it has been possible to identify a broad range of SDG-related factors that could be included in a cost-benefit analysis. The following section looks at the role of cost-benefit analysis in advancing more sustainable water services, and makes the argument that micro-level models present the next step in identifying community-specific solutions that can also advance the 2030 agenda.

\subsection{Cost-Benefit Analysis for MUS}

Whittington et al. [35] have argued that "a key issue contributing to the difficulty in achieving improved access has been a fundamental misunderstanding of the economics of investment in the water and sanitation sector. The core problem is to ensure that the benefits of improved water and 
sanitation access will be large enough to cover or possibly exceed the costs for those who will bear them: yet surprisingly often, this need is overlooked" (p. 472).

Quite apart from the fact that the costs of improvement have often to be borne by people not directly benefiting from the actual improvement (for instance, economically well-off people in cities often pay tax subsidies to improve water facilities in rural areas), there is also the issue that water, being essential for human activity, is already available in some limited form and hence any improvement may be "incremental" in benefit. On the other hand, the provision of a non-essential good such as electricity has a significant effect on lifestyles and hence may be seen as more beneficial in the short-run [35].

This "paradox" [35] (p. 472) could be at least partially responsible for relative failures in water projects beyond strictly technical or managerial reasons. Hence, to ensure SDG 6 is met and that MUS projects are undertaken that broadly impact the SDGs, it would be worth undertaking a cost-benefit analysis prior to implementing any project.

A basic cost-benefit model looks at the net benefits $(N B)$ in terms of a difference between the estimated benefits $(\bar{B})$ and the estimated costs $(\overline{\boldsymbol{C}})[35]$ :

$$
N B=\bar{B}-\bar{C}+\eta
$$

where $\eta$ is the error in estimating benefits and costs that may be different from the true benefits and costs.

It is possible to estimate the incremental costs of upgrading an existing system to provide MUS $[18,34]$. Similarly, the benefits may be estimated based on the multiple uses of water for a particular country's sample by considering the interconnected relationships between water and other SDG targets and specifying all the benefits in terms of a common unit. The net benefits may then be calculated for a particular country or community from the estimated costs and benefits.

Whittington et al. identify four possible approaches to performing a statistically sound cost-benefit analysis. The most "correct" approach that would account for variability across samples (here, the samples are the results from different water development projects) would be to randomly sample potential water and sanitation projects in developing countries and apply cost-benefit models to this sample of locations to obtain potentially generalizable results. A second approach would be to select a small number of representative locations and then collect site-specific, accurate information on the parameter values in the cost-benefit model and use these as indicators of the overall costs and benefits. A big challenge with these two approaches is that few donor organizations are willing to invest the needed resources to collect such data. A third approach would be to calculate the benefits and costs for each country or region in the world, using country- or region-specific information from global databases for those parameters for which such data are available. For parameters for which such secondary data are not available for each country or region, evidence from a few site-specific studies or professional judgment could be used [36]. The fourth approach would be construct a probability distribution of costs and benefits using parameters sampled from a reasonable distribution based on previous studies—-the approach adopted by Whittington et al. [35].

In all these methods, the drawback is that true generalization may not even be possible given the extreme specificity of developmental needs in different locations. It is feasible to specify a good site-specific cost-benefit model that can be used to evaluate the impact of interventions [36-40]. The Powers [37,38] and Lovei and Whittington [39] models were developed to analyze the costs and benefits of specific development projects under consideration for donor funding, while the Hutton and Haller [36] and WHO [41] approaches use a country-specific, instead of a location-specific, model to generate a global picture of costs and benefits of all potential water and sanitation investments. Direct extensions of these models to new MUS projects is often not feasible due to the lack of a unified data collection and modeling framework. In this paper, we suggest that a unified modeling framework with multilevel models, specified as natural extensions of random effects models that allow for location-specific variation, can be used to develop MUS interventions that advance the 2030 agenda. While this approach needs to be supported by a uniform data collection mechanism where all relevant 
information pertaining to the variables in the model are collected from different sites, it is possible to demonstrate how the framework could be applied using data available to the authors. The modeling framework is discussed in more detail in the Methodology section.

\subsection{Macro vs. Micro}

One potential problem when conducting a model-based cost-benefit analysis, is that an efficient model that focuses on macro- or system-level variables, while informative at providing clear policy prescriptions to decision-makers, does not account for variability within communities (i.e., between households) in the region under study. Even if water systems stay the same within a community, other factors such as education, number of children in the household, employment characteristics, etc., vary widely. Ignoring this variability among households may lead to sub-optimal results in policy interventions. For instance, a family with well-educated adults and in well-paying jobs might design its own interventions (e.g., boiling water before drinking or using a chlorine disinfectant) independent of the water service to ensure a reduction in gastro-intestinal illnesses. For such a family, an investment in an upgraded water system is likely to yield a smaller benefit than for a family that cannot or does not use such interventions.

Given the range of ways in which an MUS approach could be implemented [26,27], having a method that uses household-level variables to tailor an MUS intervention to maximize its overall impact is important. A one-size-fits-all "cookie-cutter" approach to designing policy interventions is likely to severely distort the actual costs and benefits and result in a flawed intervention. In the following section, a micro-level model is developed that takes into account the actual variation between households in terms of characteristics such as quantity of water used, number of children in a household, etc., to better account for the actual economic impacts of a water service upgrade.

\section{Methodology}

The purpose of this paper is to demonstrate how a micro-level modeling framework can be developed to consider the costs and benefits of MUS interventions and how these connect with SDGs and targets. The data selected for the analysis was collected during a 2013 follow-up study for an impact evaluation of a Millennium Challenge Corporation (MCC)-funded rural water supply project in the Nampula province of Mozambique [42,43]. The 2013 study was undertaken in compliance with research protocol 11-224, approved by Virginia Tech's Institutional Review Board. The follow-up study included 1826 household surveys in 62 communities (32 treatment and 30 comparison), covering topics such as household characteristics, access to water and sanitation, child health, and income and expenditure. Both the household survey and raw data are publically available [43].

The Mozambique project focused on the installation of handpumps combined with hygiene education, so it does not present an ideal example of MUS. However, the high quality of the household survey data (see [44] for an example of the data collection and cleaning process used in Mozambique) makes it possible to study the broader impacts of rural water services provision, irrespective of the project's focus. Put differently, the data is of sufficient quality to demonstrate how the micro-modelling approach can be applied, but not of sufficient focus to enable us to match theoretical variables with observed variables. Since the project focused on improving access to improved water and hygiene education, we expect the water-related economic benefits to be somewhat limited. Although, there is evidence that rural households use their available water supply to support all of their domestic and productive needs, irrespective of the quantity of water used [7]. Thus, water obtained from handpumps could support limited levels of productive activity.

Based on the interconnected relationships between the SDGs as specified in Table 1, we focus on four main benefits due to improved water access: (1) direct economic benefits-these include the potential reduction in the actual cost of buying water and possible use of water to generate an income; (2) indirect economic benefits-these include the opportunity cost associated with long walking and waiting times for water, especially in rural settings with unimproved water; (3) healthcare 
benefits-these include reduction in Costs of Illnesses (COI) avoided, and also reduction in child mortality, morbidity, etc.; and (4) nutritional benefits-these include the consumption of food produced via water-related productive activities and, to a lesser extent, reduction in hunger due to provision of safe water. Table 1 lists other benefits such as dynamic benefits of water provision in terms of speeding up economic growth. In this paper, we focus only on the direct and indirect immediate benefits due to the provision of new water services and these can be weighed against the costs of providing these services. These direct and indirect benefits correspond to variables that are used to illustrate the benefits of improved water access in the literature [36,45]. Other variables corresponding to further SDG targets can be added directly to the model to expand its application.

Using the Mozambique data, we model the individual-level benefits (or costs) associated with water access. We use the multilevel modeling/random effects regression modeling framework [46] to model the income gained (or potentially lost) due to the current level of water access. Specifically, the model for each individual household is given by,

$$
\begin{gathered}
\text { Inc }_{i}=\alpha_{j[i]}+\beta_{j[i]} \text { direct }_{\text {ProfitUse }}+\beta_{j[i]}{ }^{\text {cost }} \text { Use }_{i}+\beta_{j[i]} \text { ill }_{\text {Ill }}+\beta_{j[i]}{ }^{\text {food }} \text { Food }_{i} \\
+\beta_{j[i]} \text { indirect }_{\text {Indirect }}+\epsilon_{i}
\end{gathered}
$$

In Equation (2), the subscript $i$ is the index for the household, and $j[i]$ is the index for the community which the household $i$ is part of. Thus, the coefficient $\alpha_{j[i]}$ in the regression model is the average wage earned when the other variables are all 0 (or equivalently when there is no direct or indirect benefit due to the water access), and it is modeled as a random effect that depends on the community / country in which the data was collected for the particular household. In the full multilevel model, the random effect may itself be modeled using other predictors (for instance, education, wage earned by occupation, etc.). These variables, such as education levels, are important predictors of household income, and by ignoring these in the current iteration of the model, we fit only a very small part of the variance in the household income data. However, in this paper, we focus only on the part of income that relates to water and note that this model can be extended in future work. Similarly, the slopes $\beta_{j[i]}$ are also modeled as coefficients of random effects and vary with community/country.

The following variables are measured in units of per capita per day for the sake of consistency and all coefficients are chosen to correspond to currency units. Inc is the total income earned/reported, ProfitUse relates to the direct income earned due to water-related services, Use is the total quantity of water used, Ill is the number of water-related illnesses in a month, Food corresponds to the food-related uses of water, Indirect corresponds to opportunity costs due to not having good water access and encodes walking and waiting times to water sources. $\epsilon_{i}$ is the modeling error term which is assumed to be independent and normally distributed. Additional factors corresponding to further benefits of improved water access can be added as additional terms in this model specification.

The logic of the regression model is to look at the series of costs and benefits of having a particular level of water access and account for these as increases or decreases from the average income that potentially could be earned $\left(\boldsymbol{\alpha}_{j[i]}\right)$ by similar households in that community. A particular household that has a number of ill people due to water-related diseases is potentially losing out on their income and, hence, it is likely that the actual reported income is lower than $\alpha_{j[i]}$. Similarly, if a particular household profits directly from water, it is likely to report an income higher than the average income for the community/country under the assumption of no income effects related to water access. Based on this, the coefficients $\beta$ should all be negative except for $\beta^{\text {direct }}$ that should be positive.

The coefficients also have a direct interpretation in terms of variables that are reported in the literature. For instance, $\beta_{j[i]}$ ill represents the Cost of Illness (COI) as experienced by the particular community as it represents the decrease in income (assuming the coefficient is negative) for each unit increase in the number of illnesses in the household.

Table 2 shows how the micro-level variables relate to the six SDGs and targets identified (in Table 1) as being 'reinforced' by rural water investments. 
Table 2. Micro-level variables linking the provision of rural water supply services to SDGs and targets.

\begin{tabular}{|c|c|}
\hline SDG Goal & Variables \\
\hline Goal 1: End poverty in all its forms everywhere & $\begin{array}{l}\text { Variable: ProfitUse } \\
\text { (Direct income earned from water-related } \\
\text { services-e.g., USD } \$ / \text { LPCD) }\end{array}$ \\
\hline $\begin{array}{l}\text { Goal 2: End hunger, achieve food security and improved } \\
\text { nutrition, and promote sustainable agriculture }\end{array}$ & $\begin{array}{l}\text { Variable: Food } \\
\text { (Nutritional benefits from access to food-e.g., } \\
\text { USD } \$ \text { / consumption of food types) }\end{array}$ \\
\hline $\begin{array}{l}\text { Goal 3: Ensure healthy lives and promote } \\
\text { well-being for all at all ages }\end{array}$ & $\begin{array}{l}\text { Variable: Ill } \\
\text { (Economic impacts of illness-e.g., } \\
\text { USD } \$ \text { / prevalence of illness) }\end{array}$ \\
\hline \multirow[t]{3}{*}{$\begin{array}{l}\text { Goal 5: Achieve gender equality and } \\
\text { empower all women and girls }\end{array}$} & $\begin{array}{l}\text { Variable: Indirect } \\
\text { (Indirect economic benefits-e.g., } \\
\text { USD\$/educated girl child) }\end{array}$ \\
\hline & $\begin{array}{l}\text { (Indirect economic cost-e.g., opportunity } \\
\text { costs of not having good water access based on } \\
\text { water collection walking and waiting } \\
\text { times-e.g., USD\$/time spent per capita per day) }\end{array}$ \\
\hline & $\begin{array}{l}\text { Variable: ProfitUse } \\
\text { (Direct income earned from water-related } \\
\text { services—e.g., USD\$/LPCD) }\end{array}$ \\
\hline $\begin{array}{l}\text { Goal 8: Promote sustained, inclusive, and sustainable } \\
\text { economic growth, full and productive employment, } \\
\text { and decent work for all }\end{array}$ & $\begin{array}{l}\text { Variable: Indirect } \\
\text { (Indirect economic benefit-e.g., } \\
\text { opportunity costs of not having good water access } \\
\text { based on water collection walking and waiting } \\
\text { times-e.g., USD } \$ \text { / time spent per capita per day) }\end{array}$ \\
\hline Goal 10: Reduce inequality within and among countries & $\begin{array}{l}\text { Variable: ProfitUse } \\
\text { (Direct income earned from water-related } \\
\text { services-e.g., USD } \$ / \text { LPCD) }\end{array}$ \\
\hline
\end{tabular}

One key assumption regarding this model is that variables corresponding to Ill, Indirect, etc., are readily available in the data. In this paper, we use variables measured from the actual survey instrument-number of children reporting stomach-related illness, total walking and waiting time to access a liter of water-as proxies for these variables. A more comprehensive design could include an intermediate factor analysis step to identify which factors affect income due to water and which observed variables correspond to these factors.

\section{Results}

Using the household survey data, we built a model for Mozambique based on the framework described in the previous section. We do not build a full multilevel model in this paper as all the data is from the same country. The variables used in the model are described below.

Income: The household income was obtained from the income module of the household survey [43] and is measured in Metical. The actual monthly household income was converted into total income per day (dividing by 30) for convenience. It was not converted into income per capita as our analysis in this paper focuses on household income. The exchange rate for conversion to US dollars is based on 2013 rates (which is when the data were collected) with 1 USD $=30$ Metical (approx.). The current exchange rate is 1 USD $=70$ Metical (approx.).

Total LPCD: The daily per capita water consumption is calculated from the water module of the household survey [43], which collected detailed information on who collected water, where they collected water from, and how may containers of what size they collected from each water source during the wet and dry season. The total quantity of water collected in a week by all individuals was converted into total liters per capita per day (LPCD). On average, households had 4.2 members. 
LPCD_unimproved: The total LPCD from "unimproved" sources, i.e., from surface water sources that are typically some distance away from the household, was obtained from the water module of the household survey and is used to model the Use variable (in Equation (2)).

$L P C D \_i m p r o v e d:$ The total liters per capita per day from "improved" sources, i.e., from handpumps which were installed in the community, was used to model the ProfitUse variable (in Equation (2)) since we do not have data on the quantity of water used for water-related productive activities.

ChildIll: The number of children in the household reporting stomach illness was obtained from the health module of the household survey [43], which collected data on the number of children reporting gastrointestinal disorders or diarrhea in the household over the past week. The ChildIll variable was used to model the Ill variable (in Equation (2)). It was assumed that all child illnesses (stomach-related illnesses only) were due to the water source since sufficient water quality data were not available. In future iterations of the model, this variable could be modified by assuming a treatment effect for households accessing improved water sources, or by including a water quality variable.

MPCD_unimproved: The total minutes per capita per day spent collecting 1 liter of water from "unimproved" sources, was obtained from the water module of the household survey [43], and used to model the Indirect variable (in Equation (2)).

$I M P R_{i}$ : This dichotomous variable takes values 1 or 0 and indicates whether a particular household belongs to a community corresponding to the treatment group (community with access to handpump) or to the control group (no handpump access). In the current dataset with 1826 households, 972 households belong to the treatment group whereas the other 854 households belong to the control group.

In our model, we separate the treatment and control households using the indicator variable to estimate the cost of illness for the two groups separately. This is because there is a possibility that the illness alleviation effect of MUS may be confounded in this particular study where we do not specifically control for disease spreading mechanisms through water. In future studies, it would be useful to explicitly control for such mechanisms when studying the health-related aspects of water to avoid confounding due to other variables.

Other variables such as Agricultural Income, Child mortality, etc., were considered for the model variables Profit Use and Ill, but the models were not substantially more informative due to adding these variables, and hence they were omitted. The summary statistics for these variables are shown in Table 3. The empirical data show extreme variability in the variables among the households surveyed, and this is often a feature of self-reported income and water consumption data, which again needs to be addressed in a future study which aims at finding robust results.

Table 3. Summary statistics for data variables used in modeling.

\begin{tabular}{ccccc}
\hline Variable & Min & Mean & Max & Standard Deviation \\
\hline Income per day & 1 & 119.8 & 3203 & 219.27 \\
\hline Total LPCD & 0 & $20.64(20.44){ }^{*}$ & 75 & $10.98(10.1)^{*}$ \\
\hline LPCD_improved $^{*}$ & 0 & 9.075 & 71.43 & 12.49 \\
LPCD_unimproved $^{*}$ & 0 & 11.35 & 75 & 12.24 \\
Child Ill per day & 0.2857 & 0.023 & 0.857 & 0.078 \\
\hline MPCD_unimproved $^{*}$ & 0 & 56.23 & 850 & 87.89 \\
\hline
\end{tabular}

* These values for average LPCD and standard deviation of LPCD are obtained after excluding four extreme values recorded that were greater than $80 \mathrm{LPCD}$, much higher than for the rest of the data.

With the data variables substituted in the model, and using income per day as the dependent variable, we obtain the following regression model:

$$
\begin{array}{r}
\text { Inc }_{i}=121.3+ \\
+0.52 L P C D \_ \text {improved }_{i}-0.28 \text { LPCD }_{\text {unimproved }}-116.67 \text { ChildIll }_{i} \\
\\
* I M P R_{i}+49.7 \text { ChildIll }_{i} *\left(1-I M P R_{i}\right)-0.05 M P C D_{\text {unimproved }_{i}}
\end{array}
$$


This model suggests that the average daily income for households drawing the average quantity of water per capita per day from unimproved sources is roughly 121.3 Metical, which is close to 2 USD in current exchange rates. (The exchange rate has more than doubled since the data was collected and hence this would have corresponded to around 4 USD under the then-prevailing rates.) However, the average income per capita per day (ignoring the effect of other variables) is 119.8 Metical (as seen in Table 3) and the difference of 1.5 Metical (121.3-119.8) is due to the costs of illness of children and the opportunity cost of spending time on collecting unimproved water (net of the positive benefit due to using water from improved sources).

The coefficient -0.28 for $L P C D \_$unimproved suggests that the indicated cost for water use from the unimproved water sources is 0.28 Metical per 1 LPCD. The usage of water from improved sources in itself correlates to an increase in income and this is reflected in the positive coefficient for the variable $L P C D \_i m p r o v e d$. When considering the increase in usage of improved water from handpumps, an increase of 1 LPCD corresponds to an increase of 0.52 Metical in income per capita per day. The cost of illness (COI) indicated for a household in the treatment group in this dataset is given by 116.67 Metical (equivalent to an average day's income and about 4 USD per child per day under then-prevailing rates) and is measured by the coefficient of the data variable ChildIIl*IMPR. This COI measure reflects the actual cost of illness for the families in this dataset as opposed to other reported COI measures that typically provide an average for the whole country. We use the number of children who are ill (normalized to per day units) as the proxy for the cost of illness because child illness is an important reason for both lost income due to hospital visits and direct costs of paying for these visits. In future data collection, more indicators of illness may be used to accurately estimate the COI. For households in the control group, the coefficient of +49.7 indicates a positive correlation, which is an anomaly in the dataset and is not supported in theory. This change in sign, coupled with the fact that the regression coefficient is not significant suggests that the variable we have selected does not capture adequately the actual processes involved due to limitations in the dataset mentioned above.

The indirect costs due to limited water access are measured using total time spent in minutes per capita per day to obtain one liter of unimproved water. This represents the opportunity cost/income foregone due to time spent walking to the water source and waiting at the source. The coefficient $-0.05 \mathrm{Metical}$ is the indirect cost of not having direct access to water and measures the decrease in income due to each extra minute spent collecting water relative to the average of all households.

\section{Discussion}

Whittington et al. [35] provide a general template for providing a statistically reliable cost-benefit analysis of water access interventions in multiple project sites. This paper provides the multilevel modeling framework to accommodate such a generalizable analysis. To obtain the specific benefits of the water intervention as experienced by the individual households, we build a regression model where the response variable is taken to be the income of a household and all the impacts due to the interconnectedness of the development targets are measured in currency units to provide equivalent economic costs and benefits. Due to its modular nature, this framework can be expanded to accommodate additional variables that explain the variation in income due to any additional sources. In this paper, we only look at the net benefits due to water-related effects and do not consider the costs of building and maintaining the water infrastructure, since we did not have access to these data. We note, however, that once the benefits of the water intervention are computed, assuming fixed costs (capital, labor, interest, fees, maintenance, etc.), the cost-benefit accounting can be completed by comparing the net benefits as computed by our model with the total costs per household as provided by the cost data.

The framework used in this paper allows researchers to include the natural variability of households within a community in their analysis by proposing a micro-level model that can replace the more common macro-level models. Data for this micro-level model can be collected using appropriately designed survey instruments and will enable the computation of the actual costs and benefits of the 
intervention as experienced by the members of a particular community. For example, the model we have built infers that the community-specific average Cost of Illness (COI) as measured using the variable specified in this model is around 4 USD per day under then-prevailing rates, whereas estimates of COI are usually specified for countries and regions as a whole due to the non-availability of fine scale data.

In developing the micro-level model, the interconnected impacts of a rural water intervention to achieve SDG 6 were explored (see Table A1 in Appendix A). These interconnected impacts are well known in the water sector [23], but it is now important to explicitly link them to the SDGs and targets to inform decision-making. Whereas previous research did connect an MUS approach to the MDGs [22], it did not provide a methodology to quantify the impact of MUS interventions on broader development goals and targets. This 'proof-of-concept' paper attempts to demonstrate how such a methodology could be applied. While the water-related data available to the authors had only a modest alignment with MUS, this should not distract from the potential value of the methodology.

Using Table A1 as a starting point, it should be possible for actors in the rural water supply sector to develop a set of household-level variables that could be consistently collected to support the modeling approach advanced in this paper. The UN-Water organization-an inter-agency coordination mechanism for all water- and sanitation-related activities within the UN system-is uniquely positioned to lead such an effort (for example, see [47]). The more data that is available, the more powerful the models will become at informing which type of rural water interventions might realize the largest impact, measured in terms of the SDGs and targets. Of course, this approach will require development organizations and actors to fully engage in openly sharing their data. Fortunately, organizations such as the Millennium Challenge Corporation (MCC), the World Bank, the Bill and Melinda Gates Foundation, and others are moving in this direction, but more coordination is needed to ensure the availability of, and consistency across, household-level data sets. An additional challenge with micro-level data is the need to protect the identify of respondents, which may limit both the resolution of household-level data (due to top coding and other anonymization techniques) and the ability to know where a community is located. The MCC is perhaps at the forefront of grappling "with the ethical, legal, and practical issues related to pubic release of microdata" [48] (p. 1), which would be essential if a micro-level modeling approach were to be broadly adopted. In this analysis, the authors had full access to the Mozambique data. However, the household-level data that is publicly available [43] has been anonymized, which means that the exact model presented cannot be replicated. However, the publicly accessible data can be used to inform models in other regions of Mozambique and Africa. An important area of discussion is how can development organizations establish research protocols that can protect survey respondents, while providing sufficient data to support micro-level models.

The general approach advanced in this paper also runs counter to many rural water projects that typically focus on the installation of one type of intervention across a region. The rationale for this approach is that it can generate economies of scale and establish markets for the spare parts needed to maintain and repair water systems. However, what the current failure of around one-third of installed rural water systems across Africa [28] indicates is that a more tailored approach that attempts to maximize the benefits of a rural water intervention to a community may help improve system sustainability and advance a range of SDGs.

In this paper, an ideal MUS approach is advanced due to the broad range of impacts that can be realized from providing water for both domestic and productive activities. There is growing evidence that an MUS approach can realize significant economic impacts $[15,20,24,49]$ and generate sufficient income to repay (in theory) the costs of upgrading a rural water supply system to MUS in around one year $[18,34]$. If the micro-level modeling approach developed in this paper were applied to a future MUS project, the empirical results would provide valuable insights into the broader impacts of MUS (specifically, how the SDGs and targets are influenced), and indicate how these can be further improved through targeted interventions. It is also important not only to capture the baseline 
conditions so targeted interventions can be made, but also to undertake follow-up studies so the micro-level model can be validated and improved for future projects. As argued above, the more data that can be collected in a consistent manner, the more valuable the models become. If such an approach could be advanced, the elements studied from an MUS context could also be refined or expanded (e.g., energy supply options could be considered alongside water, health, and livelihood improvements) to advance sustainable development goals. Of course, such an integrated service delivery —or nexus [50] — approach would require governments and development organizations to adopt a multi-purpose design for programs and projects. Advancing such programs or projects will be challenging in an environment where separate agencies or organizations typically exist for water, irrigation, energy, economic development, health, etc., and where the use of funds is usually constrained by institutional missions or policy mandates. It is important, therefore, to consider how the SDGs and targets could be used to help bridge existing disciplinary and funding silos. We believe the analysis captured by Table A1 (in Appendix A) is one way to highlight connections that may exist between a holistic water intervention and sustainable development objectives. Such a table could be further developed in partnership with actors in the irrigation, health, energy, etc., sectors, with the objective of specifying a more comprehensive micro-level model. This empirical understanding in terms of multi-pronged impacts will inform the development of a more sophisticated model than the one used for illustration in this paper, which would, in turn, provide a more accurate accounting of costs and benefits resulting from new water services.

Finally, the adoption of a micro-level modeling approach to design integrated development projects and programs, is likely to be enabled by the growing use of mobile data collection platforms that continue to reduce the technological and cost barriers related to household-level data collection.

\subsection{Limitations}

The authors recognize that the model presented in this paper is extremely limited in scope. For instance, it does not include any important predictor variables for income (e.g., education levels, job opportunities, etc.) and hence has very low explanatory power. Also, while the intercept is significant at the $95 \%$ level, the standard errors of the other coefficients are high and most of them are not significant. These results, while undesirable in a predictive model, are quite expected in this particular case, since we have arbitrarily chosen these data variables to substitute for the model variables due to the fact that the data collection step did not anticipate the building of such a model. Nonetheless, the model still provides an indication of the interconnectedness of water to a range of socio-economic outcomes.

Another key limitation of our presentation is that we have suggested that a multilevel modeling framework be used to allow for transferability of knowledge between different project sites. We have, however, illustrated it with data from only one country-Mozambique. To demonstrate the full potential of the modeling framework, it needs to be applied it to multiple project sites that have been studied in a consistent way.

\subsection{Future Research}

There needs to be a concerted effort in the development of SDG indicators to ensure that the data collected can be used to advance decision-making, not just track progress. The development community has an opportunity to reorient its focus on the SDG process to look in an informed way at the future. While this paper provides an example of how a micro-level modeling framework can be developed, the analysis was limited by not having access to multi-project/multi-country data. Future research is needed to extend the modeling approach to demonstrate how the modeling results can be used to tailor future interventions to the specific needs of communities and to realizing a broad range of interconnected SDGs and targets. Given the range of ways in which water interventions (and interventions in other sectors) can be implemented, having a modeling approach that uses household-level variables to tailor an intervention to maximize its overall impact will be important. 


\section{Conclusions}

This paper attempts to map the relationships between an MUS approach to delivering rural water services and other development goals and targets to demonstrate the interconnectedness of the SDG framework. This interconnectedness presents a new frontier for designing projects and programs that address the specific needs of communities while also leveraging the knowledge gained from previous projects in any country. The paper shows how a micro-level modeling approach can be used to achieve both of these objectives. While this paper studies how the provision of rural water services could impact the 2030 agenda, the methodology used can also be applied to other sectors-e.g., health, energy, etc.- - to study how a specific service delivery/development approach may impact development outcomes within and outside of a specific sector.

The micro-level model provides donor organizations and governments with a means to quantitatively assess the development impacts associated with an intervention. However, for the approach to be successful, these actors need to collect data in a consistent way and make these data available via open data platforms.

Acknowledgments: The authors would like to acknowledge the work of the MCC-impact evaluation team who collected the data used in this paper. We would especially like to thank Eric A. Vance and Marcos Carzolio for their work in cleaning and processing these data. The authors would also like to thank the survey respondents in the province of Nampula, Mozambique, who kindly agreed to participate in the study. The MCC-impact evaluation was funded by the Millennium Challenge Corporation.

Author Contributions: R.P.H. led the MCC-impact evaluation team that collected the data used in the analysis. R.P.H and S.R. developed the methodology and wrote the paper. R.G.C. provided research support and contributed to the writing of the paper. S.R. developed the model and performed the analysis.

Conflicts of Interest: The authors declare no conflict of interest. 


\section{Appendix A}

Table A1. Relationship between the provision of rural water supply services (i.e., MUS) and SDG Targets.

\begin{tabular}{|c|c|c|c|}
\hline SDG Goal & SDG Target & Influence of Water on SDG Target [3] & Relationship \\
\hline \multirow[b]{2}{*}{ Goal 1: End poverty in all its forms everywhere } & $\begin{array}{l}1.1 \text { By } 2030 \text {, eradicate extreme poverty for all people everywhere, currently } \\
\text { measured as people living on less than } \$ 1.25 \text { a day } \\
1.2 \text { By } 2030 \text {, reduce at least by half the proportion of men, women, and } \\
\text { children of all ages living in poverty in all its dimensions according to } \\
\text { national definitions }\end{array}$ & +2 Reinforcing & $\begin{array}{l}\text { The provision of water for productive activities (e.g., raising } \\
\text { livestock, small-scale agriculture can reduce poverty via } \\
\text { direct income or avoided expenditures }\end{array}$ \\
\hline & $\begin{array}{l}\text { 1.4 By 2030, ensure that all men and women, in particular the poor and the } \\
\text { vulnerable, have equal rights to economic resources, as well as access to basic } \\
\text { services, ownership, and control over land and other forms of property, } \\
\text { inheritance, natural resources, appropriate new technology, and financial } \\
\text { services, including microfinance }\end{array}$ & +1 Enabling & $\begin{array}{l}\text { Ownership and control over land is important for enabling } \\
\text { water-related productive activities } \\
\text { Access to financial services can enable households to invest } \\
\text { in the productive use of water }\end{array}$ \\
\hline \multirow{3}{*}{$\begin{array}{l}\text { Goal 2: End hunger, achieve food } \\
\text { security and improved nutrition, } \\
\text { and promote sustainable agriculture }\end{array}$} & $\begin{array}{l}2.1 \text { By 2030, end hunger and ensure access by all people, in particular the } \\
\text { poor and people in vulnerable situations, including infants, to safe, } \\
\text { nutrititious, and sufficient food all year round } \\
2.2 \text { By } 2030 \text {, end all forms of malnutrition, including achieving, by } 2025 \text {, the } \\
\text { internationally agreed targets on stunting and wasting in childden under } 5 \\
\text { years of age, and address the nutritional needs of adolescent girls, pregnant, } \\
\text { and lactating women, } \\
\text { and older persons }\end{array}$ & +2 Reinforcing & $\begin{array}{l}\text { The provision of water for productive activities can directly } \\
\text { reduce hunger via the consumption of crops and } \\
\text { livestock-related food products }\end{array}$ \\
\hline & $\begin{array}{l}2.3 \text { By 2030, double the agricultural productivity and incomes of small-scale } \\
\text { food producers, in particular women, indigenous peoples, family farmers, } \\
\text { pastoralists, and fishers, including through secure and equal access to land, } \\
\text { other productive resources and inputs, knowledge, finannial services, } \\
\text { markets, and opportunities for value addition and non-farm employment }\end{array}$ & +1 Enabling & $\begin{array}{l}\text { Ownership and control over land is important for enabling } \\
\text { water-related productive activities } \\
\text { Access to financial services and markets can enable rural } \\
\text { households to invest in the } \\
\text { productive use of water }\end{array}$ \\
\hline & $\begin{array}{l}\text { 2.4 By 2030, ensure sustainable food production systems and implement } \\
\text { resilient agricultural practices that increase productivity and production, that } \\
\text { help maintain ecosystems, that strengthen capacity for adaptation to climate } \\
\text { change, extreme weather, drought, flooding, and other disasters and that } \\
\text { progressively improve land and soil quality }\end{array}$ & +1 Enabling & $\begin{array}{l}\text { The sustainable use of water resources is necessary to realize } \\
\text { sustainable food production systems }\end{array}$ \\
\hline $\begin{array}{l}\text { Goal 3: Ensure healthy lives and promote } \\
\text { well-being for all at all ages }\end{array}$ & $\begin{array}{l}3.1 \text { By } 2030 \text {, reduce the global maternal mortality ratio to less than } 70 \text { per } \\
100,000 \text { live births } \\
3.2 \text { By } 2030, \text { end preventable deaths of newborns and children under } 5 \text { years } \\
\text { of age, with all countries aiming to reduce neonatal mortality to at least as } \\
\text { low as } 12 \text { per } 1000 \text { live births and under- } 5 \text { mortality to at least as low as } 25 \\
\text { per } 1000 \text { live births } \\
3.3 \text { By } 2030 \text {, end the epidemics of AIDS, tuberculosis, malaria, and neglected } \\
\text { tropical diseases and combat hepatitis, water-borne diseases, and other } \\
\text { communicable diseases }\end{array}$ & +2 Reinforcing & $\begin{array}{l}\text { The provision of clean water for domestic uses (e.g., } \\
\text { drinking, cooking, washing, and bathing) is critical to } \\
\text { reducing mortality and water-borne diseases } \\
\text { The appropriate design of water services can reduce } \\
\text { water-related vectors/diseases such as malaria }\end{array}$ \\
\hline $\begin{array}{l}\text { Goal 4: Ensure inclusive and equitable quality education } \\
\text { and promote lifelong learning opportunities for all }\end{array}$ & $\begin{array}{l}4.1 \text { By 2030, ensure that all girls and boys complete free, equitable, and } \\
\text { quality primary and secondary education leading to relevant and effective } \\
\text { learning outcomes } \\
4.2 \text { By 2030, ensure that all girls and boys have access to quality early } \\
\text { childhood development, care, and pre-primary education so that they are } \\
\text { ready for primary education }\end{array}$ & +1 Enabling & $\begin{array}{l}\text { Improving access to water can reduce the water collection } \\
\text { burden, especially for girls, freeing up time for education } \\
\text { and other activities }\end{array}$ \\
\hline
\end{tabular}


Table A1. Cont.

SDG Goal

Goal 5: Achieve gender equality and empower all women and girls

Goal 6: Ensure availability and sustainable management of

\section{SDG Target}

5.1 End all forms of discrimination against all

5.5 Ensure women's full and effective participation and equal opportunities for leadership at all levels of decision-making in political, economic, and public life

5.4 Recognize and value unpaid care and domestic work through the

provision of public services, infrastructure, and social protection policies an the promotion of shared responsibility within the household and the family as nationally appropriate

5.a Undertake reforms to give women equal rights to economic resources, as Wat as access to ownership and control over land and other forms of

ind interitance, and natural resources, in accordance

.b Enhance the use of enabling technology, in particular information an

.

6.1 By 2030, achieve universal and equitable access to safe and affordable
drinking water for all

6.2 By 2030, achieve access to adequate and equitable sanitation and hygiene for all and end open defecation, paying special attent
women and girls and those in vulnerable situations

women and girls and those in vulnerable situations

6.3 By 2030, improve water quality by reducing pollution, eliminating

dumping, and minimizing release of hazardous chemicals and materials,

recycling and safe reuse globally

6.4 By 2030, substantially increase water-use efficiency across all sectors and

the number of people suffering

from water scarcity

6.5 By 2030, implement integrated water resources management at all levels,

including through transboundary cooperation as appropriate
$6.6 \mathrm{By} 2020$, protect and restore water-related ecosystems, including

mountains, forests, wetlands, rivers, aquifers, and lakes

6.a By 2030, expand international cooperation and capacity-building support

to developing countries in water- and sanitation-related activities and
programmes, including water harvesting, desalination, water efficiency,

programmes, including water harvesting, desalination,
wastewater treatment, recycling, and reuse technologies

6.b Support and strengthen the participation of local communities in
improving water and sanitation management
Influence of Water on SDG Target [3]

Relationship

+2 Reinforcing

Ensuring the equal participation of women in the selection
operation, and management of water supply services will support efforts to reduce discrimination and improve women's participation in leadership and decision-making roles

As the primary water collectors, improving access to water and reproductive activities

Ownership or control over land by women is important for Access to financial services and markets can enable wom Access to financial services and markets can enable women
to invest in the productive use of water

The use of communication technology by women to track, services or the price of a crop in the market can promote their engagement in the management of water services and water-related income generating activities

The MUS approach provides improved access to safe drinking water, along with greater a
domestic and productive activities

+3 Indivisible

The MUS approach considers how the health benefits of water services might be optimized through hygiene or

The MUS approach focuses on protecting critical water sources for sustainable water supply, which requires that
waste and wastewater be managed appropriately

The MUS approach focuses on using multiple water source for multiple uses in the most efficient way possible-e.g.". using drip irrigation

The MUS approach provides access to water within the context of sustainable water resources
management, which includes the protection and restoration of critical water sources

The MUS approach can use any water harvesting, water that are suitable for resource poor settings technologies MUS is a participatory and gender inclusive whole-water
approach, focused on aligning domestic and productive approach, focused on aligning domestic and productive water needs with available water sources, within the contex
of sustainable water resources management 
Table A1. Cont.

\section{SDG Goal}

SDG Target

Goal 7: Ensure access to affordable, reliable, sustainable, and
modern energy for all

7.1 By 2030, ensure universal access to affordab

7.2 By 2030, increase substantially the share of

renewable energy in the global energy mix

8.1 Sustain per capita economic growth in accordance with nationa

8.1 Sustain per capita economic growth in accordance with national
circumstances and, in particular, at least 7 percent gross domestic product

growth per annum in the least developed countries

8.2 Achieve higher levels of economic productivity through diversification technological upgrading, and innovation, including through a focus on
high-value added and labour-intensive sectors

3 Promote development-oriented policies the

8.3 Promote development-oriented policies that support productive
activities, decent job creation, entrepreneurship, creativity, and innovation,

and encourage the formalization and growth of micro-, small-, and

medium-sized enterprises, including through access to financial services

9.1 Develop quality, reliable, sustainable, and resle, to support economic development and human well-being, with a focus on affordable and

Goal 9: Build resilient infrastructure, promote inclusive and sustainable industrialization, and foster innovation

9.3 Increase the access of small-scale industrial and other enterprises, in
particular in developing countries, to financial services, including affordab particular in developing countries, to financial services, in
credit, and their integration into value chains and markets

10.1 By 2030, progressively achieve and sustain income growth of the bottom 40 percent of the population at a rate higher than the national average

10.2 By 2030, empower and promote the social, economic, and political

religion, or economic or other status

10.3 Ensure equal opportunity and reduce inequalities of outcome, includin by eliminating discriminatory laws, policies, and practices and promoting

$11.5 \mathrm{By} 2030$, significantly reduce the number of deaths and the number of

Goal 11: Make cities and human settlements inclusive, safe,
resilient, and sustainable

people affected and substantially decrease the direct economic losses relative

water-related disasters, with a focus on protecting the poor and people in vulnerable situations

12.2 By 2030, achieve the sustainable management and efficient use of atural resources

13.1 Strengthen resilience and adaptive capacity to climate-related hazards
and natural disasters in all countries

and production patterns 13.3 Improve education, awareness-raising, and human and institutional capacity on climate change mitigation, adaptation, impact reduction, an

Goal 13: Take urgent action to comb

Goal 15: Protect, restore, and promote sustainable use of 15.1 By 2020, ensure the conservation, restoration, and sustainable use of terrestrial ecosystems, sustainably manage forests, combat terrestrial and inland freshwater ecosystems and their services, in particular international agreements
Influence of Water on SDG Target [3] Relationship

+1 Enabling

The use of renewable energy to move water may increase access to energy services around the water pumping system

mproving access to water services will reduce the time spent collecting water and enable individuals, especially women, to engage in income generating activities or domestic activities that support Access to financial services and markets can enable rura
households to invest in income-generating productive activities that rely on water

The creation of sustainable and resilient rural water supply
services will help build community resilience and support economic development

+1 Enabling

Improving rural community access to financial services and their water-related productive activities, respectively

The provision of water for productive activities can promote income growth, especially for the poorest 40 percent of the
population who tend to live in rural areas

+2 Reinforcing

nsuring the equal participation of men and women in the selection, operation, and management of water supply services will support efforts to promote inclusion and equal opportunity

The protection and restoration of water sources combined with the provision of multiple sources for multiple uses
could reduce the impact of a water-related disaster and provide some level of water access during a disaster event, respectively

Integrating a rural water service strategy with available water resources can promote the sustainable management of these resources

Designing sustainable and resilient rural water supply
services using participatory processes can increase community resilience and enhance community awarenes about climate change

Integrating a rural water service strategy with available water resources can promote the sustainable use of
freshwater ecosystems 


\section{References}

1. United Nations (UN). Transforming our World: The 2030 Agenda for Sustainable Development; Resolution Adopted by the General Assembly on 25 September 2015, A/res/70/1; United Nations: New York, NY, USA, 2015.

2. Spaiser, V.; Ranganathan, S.; Swain, R.B.; Sumpter, D.J.T. The sustainable development oxymoron: Quantifying and modelling the incompatibility of sustainable development goals. Int. J. Sustain. Dev. World Ecol. 2016. [CrossRef]

3. Nilsson, M.; Griggs, D.; Visbeck, M. Map the interactions between sustainable development goals. Nature 2016, 534, 320-322. [CrossRef] [PubMed]

4. GBD 2015 SDG Collaborators. Measuring the health-related sustainable development goals in 188 countries: A baseline analysis from the global burden of disease study 2015. Lancet 2016, 388, 1813-1850.

5. Meier, B.M.; Kayser, G.L.; Amjad, U.Q.; Bartram, J. Implementing an evolving human right through water and sanitation policy. Water Policy 2013, 15, 116-133. [CrossRef]

6. Gleick, P.H. The human right to water. Water Policy 1998, 1, 487-503. [CrossRef]

7. Hall, R.P.; Van Houweling, E.; Van Koppen, B. The human right to water: The importance of domestic and productive water rights. Sci. Eng. Ethics 2013, 20, 849-868. [CrossRef] [PubMed]

8. Langford, M. The united nations concept of water as a human right: A new paradigm for old problems? Water Resour. Dev. 2005, 21, 273-282. [CrossRef]

9. United Nations Human Rights Council (UNHRC). Report of the United Nations High Commissioner for Human Rights on the Scope and Content of the Relevant Human Rights Obligations Related to Equitable Access to Safe Drinking Water and Sanitation under International Human Rights Instruments; A/hrc/6/3; United Nations: New York, NY, USA, 2007.

10. Winkler, I.T. The Human Right to Water: Significance, Legal Status, and Implications for Water Allocation; Hart Publishing: Oxford, UK, 2012.

11. United Nations Development Programme (UNDP). Human Development Report 2006. Beyond Scarcity: Power, Poverty and the Global Water Crisis; United Nations Development Programme: New York, NY, USA, 2006.

12. United Nation Children's Fund (UNICEF); World Health Organisation (WHO). Progress on Sanitation and Drinking Water-2015 Update and MDG Assessment; UNICEF and WHO: Geneva, Switzerland, 2015.

13. United Nations Educational, Scientific and Cultural Organization (UNESCO). The United Nations World Water Development Report 2015. Water for a Sustainable World; United Nations Educational, Scientific and Cultural Organization (UNESCO): Paris, France, 2015.

14. United Nations Human Rights Council (UNHRC). Resolution 15/9. Human Rights and Access to Safe Drinking Water and Sanitation; United Nations: New York, NY, USA, 2010.

15. Moriarty, P.; Butterworth, J.; van Koppen, B. Beyond Domestic. Case Studies on Poverty and Productive Uses of Water at the Household Level; Irc technical Paper Series, No. 41; IRC International Water and Sanitation Centre: Delft, The Netherlands, 2004.

16. Thompson, J.; Porras, I.T.; Tumwine, J.K.; Mujwahuzi, M.R.; Katui-Katua, M.; Johnstone, N.; Wood, L. Drawers of Water II. 30 Years of Change in Domestic Water Use E Environmental Health in East Africa; International Institute for Environment and Development: London, UK, 2001.

17. Van Koppen, B.; Smits, S.; Moriarty, P.; de Vries, F.P.; Mikhail, M.; Boelee, E. Climbing the Water Ladder: Multiple Use Services for Poverty Reduction; IRC International Water and Sanitation Centre and International Water Management Institute: The Hague, The Netherlands, 2009.

18. Renwick, M.; Joshi, D.; Huang, M.; Kong, S.; Petrova, S.; Bennett, G.; Bingham, R.; Fonseca, C.; Moriarty, P.; Smits, S.; et al. Multiple Use Water Services for the Poor: Assessing the State of Knowledge; Winrock International: Arlington, VA, USA, 2007.

19. Smits, S.; Van Koppen, B.; Moriarty, P.; Butterworth, J. Multiple-use services as an alternative to rural water supply services: A characterisation of the approach. Water Altern. 2010, 3, 102-121.

20. Hall, R.P.; Vance, E.; Van Houweling, E. The productive use of rural piped water in senegal. Water Altern. 2014, 7, 480-498.

21. Van Houweling, E.; Hall, R.P.; Diop, A.S.; Davis, J.; Seiss, M. The role of productive water use in women's livelihoods: evidence from rural senegal. Water Altern. 2012, 5, 658-677. 
22. Van Koppen, B.; Moriarty, P.; Boelee, E. Multiple-Use Water Services to Advance the Millennium Development Goals; Research Report 98; International Water Management Institute: Colombo, Sri Lanka, 2006.

23. United Nations Department of Economic and Social Affairs (UNDESA). The Critical Role of Water in Achieving the Sustainable Development Goals: Synthesis of Knowledge and Recommendations for Effective Framing, Monitoring, and Capacity Development; United Dantions Department of Economic and Social Affairs: New York, NY, USA, 2015.

24. Van Koppen, B.; Smits, S.; del Rio, C.R.; Thomas, J.B. Scaling up Multiple Use Water Services: Accountability in the Water Sector; Practical Action Publishing: Rugby, UK, 2014.

25. Adank, M.; Van Koppen, B.; Smits, S. Guidelines for Planning and Providing Multiple-Use Water Services; IRC International Water and Sanitation Centre and International Water Management Institute: The Hague, The Netherlands, 2012.

26. Winrock International. A Guide to Multiple-Use Water Services; Winrock International: Washington, DC, USA, 2012.

27. Srinivasan, V.; Palaniappan, M.; Akudago, J.; Cohen, M.; Christian-Smith, J. Multiple-Use Water Services (MUS): Recommendations for a Robust and Sustainable Approach; Pacific Institute: Oakland, CA, USA, 2012.

28. Improve International. Statistics on Water Point Failures. Available online: http://www. improveinternational.org/2012/10/25/sad-stats / (accessed on 16 February 2017).

29. WaterAid. Sustainability Framework; WaterAid: London, UK, 2011.

30. Montgomery, M.A.; Bartram, J.; Elimelech, M. Increasing functional sustainability of water and sanitation supplies in rural sub-saharan Africa. Environ. Eng. Sci. 2009, 26, 1017-1023. [CrossRef]

31. Harvey, P.; Reed, B. Rural Water Supply in Africa: Building Blocks for Handpump Sustainability; Loughborough University, WEDC: Loughborough, UK, 2004.

32. Carter, R.; Tyrrel, S.; Howsam, P. The impact of sustainability of community water supply and sanitation programs in developing countries. Water Environ. 1999, 13, 292-296. [CrossRef]

33. Lockwood, H.; Smits, S. Supporting Rural Water Supply. Moving towards a Service Delivery Approach; Practical Action: Warwickshire, UK, 2011.

34. Hall, R.P.; Vance, E.; Van Houweling, E. Upgrading domestic-plus systems in rural senegal: An incremental income-cost (i-c) analysis. Water Altern. 2015, 8, 317-336.

35. Whittington, D.; Hanemann, M.; Sadoff, C.; Jeuland, M. The challenge of improving water and sanitation services in less developed countries. Found. Trends Microecon. 2009, 4, 469-609. [CrossRef]

36. Hutton, G.; Haller, L. Evaluation of the Costs and Benefits of Water and Sanitation Improvements at the Global Level; Water, Sanitation, and Health, Protection of the Human Environment, World Health Organization: Geneva, Swiztherland, 2004.

37. Powers, T. Benefit-cost analysis of urban water projects. Water Supply Manag. 1978, 1, 371-385.

38. Powers, T.; Valencia, C.A. Simop Urban Water Model: Users' Manual: A Model for Economic Analysis of Potable Water Projects in Urban Areas; Inter-American Development Bank Papers on Project Analysis, No. 5; Inter-American Development Bank, Economic and Social Development Department, Country Studies Division, Project Methodology Unit: Washington, DC, USA, 1980.

39. Lovei, L.; Whittington, D. Rent-seeking in the water supply sector: A case study of jakarta, indonesia. Water Resour. Res. 1993, 29, 1965-1974. [CrossRef]

40. Whittington, D.; Swarna, V. The Economic Appraisal of Potable Water Supply Projects; Asian Development Bank: Manila, Philippines, 1994.

41. World Health Organization (WHO). Global Costs and Benefits of Drinking-Water Supply and Sanitation Interventions to Reach the MDG Target and Universal Coverage; World Health Organization: Geneva, Swiztherland, 2012.

42. Hall, R.P.; Davis, J.; Van Houweling, E.; Vance, E.A.; Carzolio, M.; Seiss, M.; Russel, K. Impact Evaluation of the Mozambique Rural Water Supply Activity; School of Public and International Affairs, Virginia Tech: Blacksburg, VA, USA, 2014.

43. Hall, R.P.; Van Houweling, E.; Vance, E.A.; Carzolio, M. Mozambique: Rural Water Supply Follow-Up Study 2013; University Libraries, Virginia Tech: Blacksburg, VA, USA, 2013.

44. Seiss, M.; Vance, E.A.; Hall, R.P. The importance of cleaning data during fieldwork: Evidence from mozambique. Surv. Pract. 2014, 7, 4. 
45. Davis, J. Sanitation and Water; Copenhagen Consensus 2008 Perspective Paper; Copenhagen Consensus Center: Copenhagen, Denmark, 2007.

46. Gelman, A.; Hill, J. Data Analysis Using Regression and Multilevel/Hierarchical Models; Cambridge University Press: Cambridge, UK, 2006.

47. United Nations-Water (UN-Water). Integrated Monitoring Guide for SDG 6 Targets and Global Indicators; Version 19 July 2016; United Nations: New York, NY, USA, 2016.

48. Sturdy, J.; Burch, S.; Hanson, H.; Molyneaux, J. Opening up Evaluation Microdata: Balancing the Benefits and Risks of Research Transparency; Berkeley Initiative for Transparency in the Social Sciences: Berkeley, CA, USA, 2017.

49. Meeks, R. Water Works: The Economic Impact of Water Infrastructure; Discussion Paper 12-35; Harvard Environmental Economics Program, Harvard Kennedy School: Cambridge, MA, USA, 2012.

50. Kurian, M. The water-energy-food nexus trade-offs, thresholds and transdisciplinary approaches to sustainable development. Environ. Sci. Policy 2017, 68, 97-106. [CrossRef]

(C) 2017 by the authors. Licensee MDPI, Basel, Switzerland. This article is an open access article distributed under the terms and conditions of the Creative Commons Attribution (CC BY) license (http:/ / creativecommons.org/licenses/by/4.0/). 